\title{
Regional variation in Women's Education-Fertility Nexus in Northern and Western Europe
}

\author{
Jonas Wood I jonas.wood@uantwerpen.be \\ Leen Marynissen \\ Jessica Nisén I nisen@demogr.mpg.de \\ Peter Fallesen \\ Karel Neels \\ Alessandra Trimarchi \\ Lars Dommermuth \\ Ruben van Gaalen \\ Martin Kolk \\ Pekka Martikainen
}

This working paper has been approved for release by: Natalie Nitsche (nitsche@demogr.mpg.de),

Deputy Head of the Laboratory of Fertility and Well-Being.

(c) Copyright is held by the authors. 


\title{
Regional variation in Women's Education-Fertility Nexus in Northern and Western Europe
}

\author{
Jonas Wood $^{\mathrm{a}}{ }^{l}$, Leen Marynissen ${ }^{\mathrm{a}}$, Jessica Nisén ${ }^{\mathrm{b}, \mathrm{c}}$, Peter Fallesen ${ }^{\mathrm{d}, \mathrm{e}}$, Karel Neels ${ }^{\mathrm{a}}$, Alessandra \\ Trimarchi $^{\mathrm{f}}$, Lars Dommermuth ${ }^{\mathrm{g}}$, Ruben van Gaalen ${ }^{\mathrm{h}}$ Martin Kolk $^{\mathrm{i}, \mathrm{j}}$, Pekka Martikainen ${ }^{\mathrm{c}, \mathrm{k}}$. \\ ${ }^{\text {a }}$ University of Antwerp, Belgium \\ ${ }^{\mathrm{b}}$ University of Turku, Finland \\ ${ }^{c}$ Max Planck Institute for Demographic Research, Rostock, Germany \\ ${ }^{d}$ Swedish Institute for Social Research, Stockholm University, Sweden \\ ${ }^{\mathrm{e}}$ ROCKWOOL Foundation, Denmark \\ ${ }^{\mathrm{f}}$ University of Vienna, Austria \\ ${ }^{g}$ Statistics Norway \\ ${ }^{\mathrm{h}}$ Statistics Netherlands, University of Amsterdam, The Netherlands \\ ${ }^{i}$ Demography Unit, Department, of Sociology, Stockholm University, Sweden \\ ${ }^{j}$ Institute for Future Studies, Stockholm, Sweden \\ ${ }^{k}$ University of Helsinki, Finland
}

Funding: This research was funded by the Research Foundation Flanders (Grant No.

G096321N, Using dynamic microsimulation as an integrated modelling framework to assess the impact of individual-level and contextual factors on past and future fertility trends.). In addition, Peter Fallesen acknowledges funding from the ROCKWOOL Foundation (Grant No. 1226) and Swedish Research Council for Health, Working Life and Welfare-FORTE (Grant No. 2016 07099). Martin Kolk acknowledges Swedish funding provided by Riksbankens jubileumsfond grant no. P17-0330:1. Jessica Nisén was supported by the Academy of Finland (332863 and 320162) and the Strategic Research Council (345130). Alessandra Trimarchi was supported by the French National Research Agency (Grant Nr. ANR-16-CE41-0007-01). Pekka Martikainen is supported by the Academy of Finland (345219 and 308247). Lars Dommermuth is supported by The Research Council of Norway (287634).

\footnotetext{
${ }^{1}$ Corresponding author. Tel: +323 26553 64. E-mail address: Jonas.wood@uantwerpen.be (J.Wood)
} 


\begin{abstract}
The relationship between female education and fertility is a long-standing topic in demography, our understanding of which continues to develop. Since the turn of the century, a growing body of research has documented cross-national variation in the female educational gradient in fertility, with mostly positive gradients in Western and Northern European countries. However, such national gradients may mask important variation in the educational gradient in fertility at the subnational level. This study is among the first to use large-scale individual-level administrative data to study regional educational gradients in parity-specific fertility in Northern and Western European countries: Belgium, Denmark, Finland, France, the Netherlands, Norway, and Sweden. Adopting hazard models and model-based Synthetic Parity Progression Ratios, our results highlight considerable subnational regional variation in the educational gradient in first, second and third births. We conclude that, in addition to variation between countries, substantial within-country regional variation deserves to receive future scholarly attention. The documentation of regional variation in the female education-fertility nexus is a substantial extension of cross-national comparisons and contributes to the empirical and theoretical debate on the context-contingencies of the education-fertility nexus.
\end{abstract}

Keywords: Regional Variation - Fertility - Education - Administrative Data - Europe 


\section{Introduction}

The relation between female education and fertility is a long-standing central topic in demography, of which our understanding continues to develop. Coinciding trends of increasing female participation in higher education and the labour force since the 1950s and decreasing fertility levels, led early approaches to assume a negative relation between female educational attainment and fertility. However, the past three decades of research on the link between female education and fertility indicate that this long assumed negative association is not set in stone, as educational differences in female fertility vary considerably depending on the country, cohorts, and periods considered (Sobotka, Beaujouan, \& Van Bavel, 2017; Wood, Neels, \& Kil, 2014).

Around the turn of the century, early empirical evidence indicated a shift towards less negative and more positive educational gradients in female fertility patterns (Kravdal, 1992; Kravdal \& Rindfuss, 2008). In addition, available literature highlights that the magnitude of educational gradients in fertility depends considerably on the geographical context considered. In European comparison, some Western, and in particular Northern European countries tend to stand out with relatively flat female educational gradients in first births in combination with positive or U-shaped gradients in higher order births, especially for more recent time periods or cohorts (Andersson et al., 2009; Marika Jalovaara et al., 2019; Klesment, Puur, Rahnu, \& Sakkeus, 2014; Kravdal, 1992; Kravdal \& Rindfuss, 2008; Neels \& De Wachter, 2010; Neyer, Hoem, \& Andersson, 2017; Wood et al., 2014). These studies suggest and/or test the importance of contextual factors at the national level, such as work-family reconciliation policies (Andersson et al., 2009; Van Bavel \& Rozanska-Putek, 2010; Wood, 2019) and gender equality (Esping-Andersen \& Billari, 2015; Goldscheider, Bernhardt, \& Lappegard, 2015). 
In contrast to the existing body of literature addressing cross-national variation, our understanding of subnational regional variation in the education-fertility relationship remains limited. The tendency to use countries as the unit of analysis and exploit crossnational differences in empirical work likely masks lower level variation between subnational regions and entails a risk of limiting the development of theoretical frameworks to factors operating at the national level, otherwise known as the "wholenation bias" (Basten, Huinink, \& Klüsener, 2011; Snyder, 2001). From a theoretical perspective, there are plausible and partially documented mechanisms through which regional differences in the educational gradient in fertility may come into existence, such as regional contextual effects, composition effects, and selective migration (de Beer \& Deerenberg, 2007; Fox, Klüsener, \& Myrskylä, 2018; Hank, 2002; Kulu, 2005, 2013; Kulu \& Washbrook, 2014).

However, from an empirical perspective the lack of documentation of regional variation in the female education-fertility link can be understood as a direct result of the high data requirements, which are difficult to meet without large-scale administrative data. To our knowledge, only one previous study has investigated educational gradients in fertility at the subnational regional level (Nisén et al., 2021). This study found regional variation in the gradient, but analysed cohort fertility and did not distinguish between progression to different parities. In order to fill this gap in the literature, this article uses administrative data for Belgium, Denmark, Finland, France, the Netherlands, Norway and Sweden to study regional variation in the educational gradient in period fertility in Northern and Western Europe around the turn of the century. Its contribution is twofold. First, using large-scale longitudinal administrative data, we document regional variation in the female educational gradient in first, second and third births in Northern and Western Europe in 
the early 2000s. We show how these countries - which from a European perspective are characterised by progressively positive female educational gradients in fertility since the turn of the century - also exhibit subnational variation in the education-fertility nexus. Second, available estimates of educational fertility differentials are often cumbersome to compare across studies, as some document aggregate-level fertility indicators [e.g. Total Fertility Rate (TFR)] by geographical unit and level of education, whilst others provide micro-level associations between individuals' level of educational attainment and the hazard of childbearing (e.g. in terms of odds-ratios). This study provides both micro-level estimates of the association between women's level of educational attainment and birth hazards (presented as average marginal effects of educational attainment on birth hazards), as well as model-based regional-level fertility indicators by level of education (i.e. Synthetic Parity Progression Ratios (SPPR $1-3)$ ) (Liu et al., 2006).

\section{Background}

As a comprehensive overview of the various potential pathways interconnecting female education and fertility lies beyond the scope of this article, this section will first focus on the most common basic theoretical building blocks linking female educational attainment and fertility, regardless of geographical context or parity. The second part introduces the importance of national contexts for parity-specific fertility outcomes. Finally, we discuss plausible theoretical mechanisms which are available in the literature and potentially drive subnational regional variation. 


\subsection{Opportunity costs, income and preferences}

Three mechanisms particularly often referred to in the literature on female educational attainment and fertility are opportunity costs, income effects and preferences. First, higher educated groups witness higher opportunity costs of non-market activities, such as childrearing, due to higher returns on time invested in paid work in terms of earnings, job conditions, future employment security and potentially also job satisfaction. In contrast to early contributions emphasizing this mechanism as an explanation for a negative relation between female education and fertility (Becker, 1981; van de Kaa \& Lesthaeghe, 1986), later research has indicated that opportunity costs and the potential impact on fertility behaviour are likely to vary depending on contextual factors as well as the stage of the life course considered (Liefbroer \& Corijn, 1999). Among highly educated women in high-income contexts, a stable foothold in the labour force has become a precondition to childbearing (Kreyenfeld \& Andersson, 2014; Wood \& Neels, 2017). Hence, the negative impact of educational attainment on fertility through opportunity costs may be limited to the later timing of the onset of childbearing (Kreyenfeld, 2002; Neels \& De Wachter, 2010; Neels, Murphy, Ní Bhrolcháin, \& Beaujouan, 2017).

Second, women with higher educational qualifications are mostly found to have access to more financial resources due to higher employment probabilities and earning potential in the labour market (OECD, 2018) and a higher likelihood of having relatives and a partner with more resources (through intergenerational reproduction of socio-economic status and educational homogamy in partnerships ((Breen \& Andersen, 2012; Dribe \& Nystedt, 2013)). Although available resources may increase the demand for children as the budget constraint on fertility is weakened, theories of quantity-quality substitution may explain the absence of positive relations between income and fertility (Becker \& Lewis, 1973). 
Empirical evidence of income effects on fertility remains mixed and depends strongly on the context considered (Hart, 2015; M Jalovaara \& Miettinnen, 2013; Kornstad \& Rønsen, 2018; Vignoli, Drefahl, \& De Santis, 2012).

Third, educational differences in fertility may result from differential preferences. However, available empirical evidence is far from univocal in this respect. Although a higher interest in individual self-realisation and post-materialist values among highly educated women has been put forward as an explanation for their lower fertility (Lesthaeghe \& Surkyn, 1988; Lesthaeghe \& Van de Kaa, 1986), post-materialist attitudes do not seem to be negatively correlated to ideal family sizes and available research finds no consistent evidence of lower fertility intentions for highly educated groups across different geographical contexts (E. Beaujouan, Sobotka, \& Brzozowska, 2013; De Wachter \& Neels, 2011; Ruokolainen \& Notkola, 2002; Sobotka et al., 2015; Testa, 2014). Nevertheless, some argue that the relationship between fertility and female education is moderated by prevailing macro-level gender norms in society (EspingAndersen and Billari 2015).

2.2 National context matters: Northern and Western versus other European countries

Empirical research indicates substantial cross-country differences in order-specific and total fertility patterns by female level of education. With respect to the transition to parenthood, considerable differences are documented by level of educational attainment, with lower fertility for highly educated women at young ages and higher fertility for highly educated women later on. With respect to the final intensity of first births, most European countries exhibit persisting negative or U-shaped educational gradients (Eva Beaujouan, Brzozowska, \& Zeman, 2016; Miettinen, Rotkirch, Szalma, Donno, \& 
Tanturri, 2015; Van Bavel et al., 2018; Wood et al., 2014). However, cross-national comparisons indicate that some Northern and Western European countries - such as Belgium, Denmark, Norway, Sweden - exhibit relatively flat educational gradients in female first births among younger cohorts and more recent time periods (Andersson et al., 2009; Marika Jalovaara et al., 2019; Miettinen et al., 2015; Neyer et al., 2017; Van Bavel et al., 2018; Wood et al., 2014). Whereas similar flat educational gradients in childlessness have been found for some Eastern European countries, many estimates for other European countries indicate stronger negative educational gradients (Neyer et al., 2017; Wood et al., 2014). With respect to second births, most research documents lower second birth intensities for highly educated women in German-speaking (Klesment et al., 2014) and many Central and Eastern European countries (Klesment et al., 2014; Muresan \& Hoem, 2010; Perelli-Harris, 2008; Wood et al., 2014). This contrasts with the nonnegative or even positive associations in the Northern European countries such as Norway (Kravdal \& Rindfuss, 2008), Sweden (Hoem \& Hoem, 1989; Olah, 2003), Finland (Vikat, 2004), but also some Western European countries such as Belgium (Liu et al., 2006; Neels \& De Wachter, 2010; Wood et al., 2014), the Netherlands (Wood et al., 2014), France (Köppen, 2006; Wood et al., 2014) and the United Kingdom (Kulu \& Washbrook, 2014; Wood et al., 2014). Research on third and higher order births reports considerable evidence for relatively flat or U-shaped patterns in Western European countries such as France, Belgium or the Netherlands (Van Bavel et al., 2018; Wood et al., 2014), but also Northern European countries like Norway and Sweden (Van Bavel et al., 2018; Wood et al., 2014). As a result of the relatively weak negative, flat, or even positive educational gradients in order-specific fertility, North-western European countries, particularly the Nordic countries, are routinely found to exhibit flat, U-shaped or even positive relations 
between female educational attainment and female total fertility rates (Andersson et al., 2009; Marika Jalovaara et al., 2019; Neels \& De Wachter, 2010; Van Bavel et al., 2018).

Three country-level factors potentially moderating educational gradients in female fertility are likely to emerge in Western and especially Northern Europe. First, these countries have seen extensive educational expansion. It has been argued that countries where larger shares of women are highly educated exhibit a less selective highly educated group of women (e.g. in terms of career-orientation), which entails a less depressed fertility level for highly educated women (Adsera, 2017; Kravdal, 2001). Second, the Northern and Western European countries considered in this study have well-developed family-work reconciliation policies, such as parental leave schemes, extensive formal childcare, and labour market policies such as flexible working schemes and subsidized domestic employment services. These policies, often by design, are better tailored to highly educated career paths (Kil, Wood, \& Neels, 2018; Marx \& Vandelannoote, 2014; Marynissen, Wood, \& Neels, 2021; Van Lancker, 2017; Van Lancker \& Ghysels, 2012) and are often assumed an important determinant for relatively weak or even positive educational gradients in fertility in Northern and some Western European countries (Population Council, 2006). Third, whereas increasing female labour force participation - the so-called first stage of the gender revolution - has materialised across Europe, available literature provides evidence that the second stage - in which men take more responsibility for household and childcare tasks - is more pronounced in Western and particularly Northern European countries (Aassve, Fuochi, \& Mencarini, 2014; Hudde, 2018). This in turn potentially lowers the opportunity costs of childbearing particularly among the highly educated, resulting in less negative or more positive female educational gradients in fertility (Goldscheider et al., 2015). 


\subsection{Does regional context also matter?}

At the sub-national regional level, previous literature has identified local opportunity structures, selective internal migration and population composition as three inherently interlinked determinants of regional fertility levels (Basten et al., 2011; Hank, 2002; Kulu, $2005,2013)$. Although the empirical assessment of the impact of these dynamics on educational gradients in female fertility lies far beyond the scope of this article, we argue that these three factors are also likely to drive regional differences in the female education-fertility nexus.

The term local opportunity structures refers to different aspects of living conditions in the local context which influence the incentive structure of potential parents (Basten et al., 2011). The underlying assumption is that individual fertility decisions will occur as a function of local contextual characteristics through rational decision-making. For instance, as recent country-level evidence shows that employment is a stronger precursor of childbearing among highly educated women (Kreyenfeld \& Andersson, 2014; Wood \& Neels, 2017), it is possible that highly educated groups in particular will postpone or forgo childbearing in local contexts with high unemployment (Neels, Theunynck, \& Wood, 2012; Nisén et al., 2021). In addition, subnational regions have been found to vary considerably in the degree to which work and family life are compatible, for instance by providing more tailored flexible labour market opportunities, high formal childcare availability, or other options to outsource non-market activities (e.g. cleaning services, meal deliveries) (Andersson, Duvander, \& Hank, 2004; Baizan, 2009; Hank \& Kreyenfeld, 2003; Kreyenfeld \& Hank, 2000; Rindfuss, Guilkey, Morgan, \& Kravdal, 2010; Wood, 2019; Wood \& Neels, 2019). Furthermore, local opportunity structures also include cultural factors and social network effects which might provide input to 
individuals in terms of normative acceptance of different life course choices. Although the empirical assessment of such factors remains a challenging area of research, available research provides some indications for regional differentiation in normative patterns with respect to the family (Lesthaeghe \& Neels, 2002), as well as neighbour influences on fertility (Bergsvik, 2019).

Selective migration entails that regional contextual features (local opportunity structures) may attract groups with higher or lower fertility intentions (Basten et al., 2011; Kulu \& Washbrook, 2014). Selective migration is likely to be differentiated by level of educational attainment, with the more highly educated moving more often and their reasons for moving being more strongly connected to the development of educational and employment careers (Dawkins, 2006; Thomas, 2019). Therefore, this mechanism may also affect the regional variation in the female educational gradient in fertility. In principle, every regional contextual effect has a counterpart in terms of selective migration. A high availability of formal childcare for instance may affect fertility differently by educational level (Wood, 2019), but may also attract new residents with fertility intentions differentially by educational attainment.

Finally, the composition of different educational groups is also likely to vary depending on the region considered in a myriad of ways. For instance, the sheer size of educational groups in a region may affect the educational gradient in childbearing. The assumption that the larger the group of highly educated women, the less selective they will be in terms of career-orientation and therefore the less negative will be the educational gradient in fertility provided that suitable partners can be found, is plausible therefore not only at the national (Adserà, 2017; Goldin, 2004) but also at the subnational level. 
As a result of the simultaneous and interrelated impact of differential local opportunity structures, selective internal migration patterns and differential population composition by subnational region, we assume that, although regional educational gradients in fertility are likely to be clustered by country due to shared country-level characteristics, the female educational gradient will also be subject to non-negligible subnational regional variation.

\section{Data and Methods}

\subsection{Data}

This study uses individual-level administrative data for Belgium, Denmark, Finland, France, the Netherlands, Norway and Sweden to study the association between female educational attainment and fertility by subnational regions. A prospective research design is used, in which level of educational attainment and region of residence are measured in 2001 and subsequent fertility hazards for women age 15-49 are observed in the 20022005 follow-up period ${ }^{2}$. During the follow-up period, women at risk of a birth are observed until they (I) experience a birth, or (II) are censored due to emigration out of the country, death, a $50^{\text {th }}$ birthday, or the end of the observation period.

For Belgium, the individual microdata from the 2001 census - covering the complete residential population (Deboosere \& Willaert, 2004) - have been linked to data from the National Register, which provide information on changes in household composition in the period 2002-2005. For Denmark, microdata from Statistics Denmark's population

\footnotetext{
2 Due to data availability the time period for France consists of a cross-sectional measurement of educational attainment and region of residence in 1999 combined with a follow-up in 2000-2003.
} 
register captured $31^{\text {st }}$ December 2001 were linked to Statistics Denmark's databases for fertility, mortality, educational attainment, student enrolment, and migration. The data set for Finland is based on an 11 per cent random sample of the population present in Finland in 1987-2007, aged 15 and over in 2007 which was drawn from administrative registers and is nationally representative. Information from different registers were linked by Statistics Finland (license number TK-53-339-13). For France we used the 2016 database of the Permanent Demographic Sample (EDP), which consists of a large-scale sociodemographic panel that comprises information taken from the official publications of the registry for births, marriages and deaths along with census information. Individuals included in the EDP are selected from their date of birth, that is the people born from the $1^{\text {st }}$ to $4^{\text {th }}$ of October $^{3}$ (Couet, 2006). For the Netherlands the features of the Belgian dataset were replicated using the System of Social statistical Datasets (SSD) (Bakker, van Rooijen, \& van Toor, 2014). For Norway, data on residence, age and childbirths were extracted from annual updates of the Central Population Register (Statistics Norway, 2021) and linked to information from the National education database (Statistics Norway, 2017). For Sweden we use national population registers, taking the Swedish-born population of Sweden at the end of 2001 as our analysis population, and using monthly birth histories for population registers for the period 2002-2005.

3.2 Measurement of educational attainment and region, and sample restrictions In the four Northern European countries -, Denmark, Finland, Norway and Sweden - the information on educational attainment is based on educational registers. In the Belgian 2001 Census as well as the French EDP data, educational degrees are measured through

\footnotetext{
${ }^{3}$ An enlargement in the selection of birth dates has been implemented since 2004 and 2008 (see Couet 2006).
} 
self-reporting. In the Netherlands, educational information is based on registers combined with a large set of pooled Labour Force Surveys (LFS) and made representative via a weighting procedure for the entire population. The categorization of educational attainment in this study is based on the International Classification of Education 1997 (ISCED97), which is a standard international classification developed by UNESCO furthering the comparability of educational groups across countries (OECD, 1999). Aggregating the ISCED97 into low educational attainment (primary and lower secondary: ISCED codes 0-2), medium level of education (upper secondary: ISCED codes 3-4), and high levels of education (tertiary: ISCED codes 5-6) is a common practice (Marika Jalovaara et al., 2019; Wood et al., 2014), also adopted in this study.

As the fertility behaviour of those enrolled in education has been documented to differ substantially from those who completed their education (Kravdal, 2007; Lappegård \& Ronsen, 2005), individuals enrolled ${ }^{4}$ in education at the start of the observation window are excluded from the full sample of women aged 15-49 during the follow-up period. This approach would be problematic when investigating the causal effects of education on fertility due to reverse causality between fertility and education: women who become mothers before finishing their intended education may drop out of school earlier ${ }^{5}$ (Baizan

\footnotetext{
${ }^{4}$ Country-specific information on the measurement of enrolment is available in the online appendix.

${ }^{5}$ Additional inspections of the data show that this might be a concern only for the estimation of first birth hazard rates of young (15-21 years old) French women, during the observation window. By deleting women enrolled in education, the women at risk of first birth in that age-group, in France, become selective (only about 237 women remained in the risk-set). However, the overall educational gradient in first births in France tends to be in line with previous findings related to a similar period (Davie and Mazuy, 2010), which suggests that potential bias is limited. Another approach would be to use age at graduation
} 
\& Martín-García, 2006). However, this paper does not focus on the causal relationship between education and fertility, but rather on the regional variation of the educational gradient in fertility. In addition, first generation migrants are excluded from the sample due to the strong interrelations between migration and fertility (Milewski, 2010). We also dropped all women for whom no educational attainment is available. The follow-up resulted in 5,718,492 yearly person-observations for women at risk of a first birth, $3,210,531$ person-observations for women at risk of a second birth, and 5,614,108 personobservations for women at risk of a third birth.

For the measurement of the region of residence, depending on the country in question, either the NUTS level 1 or level 2 (Nomenclature of Territorial Units for Statistics) categorization is used. For Belgium NUTS 2 regional units are used which refer to the ten provinces (five Dutch-speaking Northern provinces: Antwerp, Limburg, East Flanders, Flemish Brabant which surrounds the capital, West Flanders, and five French or Germanspeaking Southern provinces: Walloon Brabant, Hainaut, Liège, Luxembourg, Namur) and the capital, Brussels. For Denmark the NUTS 2 categories distinguish five regions (the capital region Hovedstaden, Sjælland, Southern Denmark, Midtjylland, Nordjylland). For Finland NUTS 2 level is used, distinguishing four large regions (the capital region Helsinki-Uusimaa, South Finland, West Finland, East and North Finland). For France NUTS 1 categories according to the classification until up 2016 are adopted, distinguishing nine regions (the capital region Région parisienne, the Bassin parisien surrounding the capital, Nord, Est, Ouest, Sud-Ouest, Centre-Est, Méditerranée). For the

\footnotetext{
as a measure for exposure instead of age. However, our data do not provide information on women's age at graduation for all countries in our sample.
} 
Netherlands NUTS 1 level distinguishes four regions (Northern Netherlands and Eastern Netherlands which are generally more rural, the most densely populated Western Netherlands, and relatively urbanized Southern Netherlands). For Norway an extended version of NUTS 2 levels is expanded with an extra category for Oslo, entailing eight regions (the Akershus region surrounding the capital, Hedmark og Oppland, SørØstlandet, Agder og Rogaland, Vestlandet, Trøndelag, Nord-Norge, Oslo). Finally for Sweden NUTS 2 level distinguishes eight regions (Stockholm, East Middle Sweden, Småland and the islands, South Sweden, West Sweden, North Middle Sweden, Middle Norrland, Upper Norrland). The educational distributions of our regional samples used to estimate first, second and third birth hazards are provided in appendix (see table A1).

\subsection{Individual-level models}

To assess the relation between female educational attainment in 2001 and subsequent birth hazards in the 2002-2005 follow-up period, discrete-time event-history models with a logit link function are used. The models are late-entry models as women enter the model in 2002 at different exposures and thus contribute to the estimation of different partitions of the hazard function. Models are estimated separately for first, second, and third births. All models include (I) exposure, (II) region, and (III) educational attainment. For first births, exposure distinguishes age 15-21 (reference category), 22-28, 29-35, and 35-45, whereas for second and third births the indicator distinguishes 0-3 (reference category), 4-9 and more than 9-30 years after the previous birth. Hence, this variable captures the relatively low first birth hazards among the young and old age groups and particularly high second and third birth hazards shortly after the previous birth. Region distinguishes between the 48 regions under consideration and is included as a covariate to control for differences in fertility levels between all regions within and across countries. As birth 
hazard functions are likely to depend on the context considered, the effect of exposure is allowed to vary by region. Education captures differential birth hazards for women with a medium or high level of education, compared to their low educated counterparts (reference category). In line with the widely supported finding that the shape of first and higher order birth functions varies by level of education, the effects of exposure are interacted with level of education.

In order to assess to which degree the female education-fertility nexus varies (between countries as well as) regionally within countries, the models include an interaction between level of education and region. Thus the educational gradient in first, second and third births is allowed to vary across the 48 subnational regions in 7 countries. The results of these individual-level models will be illustrated using average marginal effects of medium and high levels of education and corresponding significance levels, by exposure.

\subsection{Subnational regional variation in Synthetic Parity Progression Ratios}

Following previous research (Liu et al., 2006; Wood \& Neels, 2019; Wood et al., 2014), we use estimated birth hazards by level of education, region and exposure to calculate synthetic parity progression ratios (SPPR) using equation 1 . The SPPR for birth order $i$ and time $t$ is calculated by taking the complement of the multiplication of the complements of the birth hazards $q$ for the first 30 years of exposure $x$. Hence we calculate Period Parity Progression Ratios for women with the same parity in the observation period. These regression-based SPPRs are used in the discussion of the results as they provide insight in the regional-level magnitude of the educational gradients in first, second and third order childbearing. 


$$
S P P R_{i}^{t}=1-\prod_{x=0}^{30}\left(1-q_{(i, x, t}\right)
$$

(equation 1)

This article focuses on the two educational percentage point contrasts in estimated SPPR, (I) between medium level and low educated groups, and (II) between highly educated and low educated groups. $\left(y=S P P R_{i}^{\text {medium }}-S P P R_{i}^{\text {low }}\right.$ or $\left.S P P R_{i}^{\text {high }}-S P P R_{i}^{\text {low }}\right)$. As the magnitude of the absolute difference in SPPR1-3 between different educational groups is by definition influenced by the overall levels of parity progression in a given region, we also present the differential SPPR for medium level and highly educated groups as a per cent of the SPPR among the low educated group $\left(\left(S P P R_{i}^{\text {medium }}-S P P R_{i}^{\text {low }}\right) /\right.$ $S P P R_{i}^{\text {low }}$ or $\left.\left(S P P R_{i}^{\text {high }}-S P P R_{i}^{\text {low }}\right) / S P P R_{i}^{\text {low }}\right)$

Finally, in order to quantify the degree of variation in the educational gradient in orderspecific fertility across regions (r), we calculate the ratio of the within countries (c) sum of squares and the total sum of squares $\left(\mathrm{SS}_{\mathrm{W}} / \mathrm{SS}_{\mathrm{T}}\right)$ (equation 2) as an indicator for the share of total variation due to subnational regional differences. Subsequently we calculate the ratio of the mean within countries sum of squares and the mean between countries sum of squares $\left(\mathrm{MS}_{\mathrm{W}} / \mathrm{MS}_{\mathrm{B}}\right)$ (equation 3) as an indicator for the relative magnitude of the subnational regional differences compared to differences between countries.

$$
\begin{gathered}
\frac{S S_{W}}{S S_{T}}=\frac{\sum_{c=1}^{k} \sum_{r=1}^{n}\left(y_{c r}-\bar{y}_{c}\right)^{2}}{n \sum_{c=1}^{k}\left(\bar{y}_{c}-\bar{y}\right)^{2}+\sum_{c=1}^{k} \sum_{r=1}^{n}\left(y_{c r}-\bar{y}_{c}\right)^{2}} \\
\frac{M S_{W}}{M S_{B}}=\frac{\frac{\sum_{c=1}^{k} \sum_{r=1}^{n}\left(y_{c r}-\bar{y}_{c}\right)^{2}}{(N-k)}}{\frac{n \sum_{c=1}^{k}\left(\bar{y}_{c}-\bar{y}\right)^{2}}{(k-1)}}
\end{gathered}
$$




\section{Results}

Figures 1-2 present the results for the educational gradient in first births, whereas the corresponding findings for second and third births are illustrated in figures 3-4 and figures 5-6 respectively. In all figures, the left-hand panel illustrates the difference between medium level and low educated women, and the right-hand panel displays the difference between highly and low educated women. Regions are consistently sorted by country and population density (from highest to lowest). Figures 1, 3 and 5 exhibit the results of the individual-level models using average marginal effects. In addition, Figures 2, 4 and 6 present the resulting absolute percentage point and proportional per cent educational differences in SPPR $1-3$. All model-based SPPRs by level of education and region are provided in appendix (see table A2).

3.1 National and regional variation in the female educational gradient in first births

Figure 1 shows that in all regions considered, first birth hazard schedules vary considerably by women's level of educational attainment. In line with well-accepted findings with respect to differential first birth schedules in the literature (Neels et al., 2017), we find clear indications of postponement and recuperation, entailing a negative educational gradient in young ages (15-21), a mixture of positive and negative associations between level of education and first births in the 22-28 age category, and a clear positive educational gradient among women aged 29 and older. However, large variation exists between the regions within and across countries. Several Danish, Swedish and Finnish regions exhibit significantly positive associations between medium levels of education and first birth hazards in the 22-28 age category. Similarly, in most Swedish regions, and all Danish and Finnish regions, positive associations between high levels of 
education and first birth hazards in the 22-28 age category are found, which contrasts with mixed associations in the Belgian, French and Norwegian regions, and consistently negative associations in Dutch regions. With respect to (the recuperation of) first births at higher ages, significant positive associations are found in all regions considered. A comparison of the magnitude of the educational effects in terms of birth hazards between regions is cumbersome as the absolute size of the effect is directly related to the level of the birth hazards in the region considered, but also as a comparison of educational gradients and their magnitude requires the integration of birth hazards into SPPRs.

Figure 2 shows considerable variation in the educational gradient in $\mathrm{SPPR}_{1}$ between countries, regardless of whether we observe the absolute difference in terms of percentage points or the per cent difference compared to the low educated reference group. However, a discussion of differential linkages between educational attainment and first birth hazards focussing solely on countries would mask considerable regional variation within countries. Model comparison tests indicate that a model allowing the educational gradient in first births to vary by subnational region significantly contributes to explaining variation compared to a restricted model, which allows varying gradients by country only $(\Delta$-2LL: $983.06 ; \Delta$ df. $82 ; \mathrm{p}<0.000)$. Figure 2 indicates that the magnitude of withincountry regional differences is typically limited compared to between-country differences (MSW/MSB). The average squared difference from the mean within a country is four to seven times smaller ( $25 \%$ for medium vs. low and $14 \%$ for high vs. low) than the average squared difference between countries and the grand mean. Although region-specific educational gradients in first births are clearly clustered by country, a considerable proportion of the total variation between regions is situated between regions within the same country, which puts forward subnational regional variation as an interesting 
dimension of variation in the female education-first birth nexus. Overall 62.81 per cent and 76.51 per cent of the total regional variation in the differential SPPR 1 among medium level and highly educated women is situated within countries (SSW/SST).

The $\mathrm{SPPR}_{1}$ results for Belgium indicate that regional variation in the educational gradient is not clearly related to the population density of the region considered. The Brussels capital region - together with Hainaut and Liège - stands out with the strongest negative $\mathrm{SPPR}_{1}$ differentials for medium level and highly educated women. This contrasts with the strongest positive educational gradients found in the regions Luxembourg and West Flanders. For instance in the latter region highly educated women exhibit a 16 percentage point, or 25 per cent higher $\mathrm{SPPR}_{1}$ compared to low educated groups, whereas the corresponding differential $\mathrm{SPPR}_{1}$ for medium level educated groups amounts to 9 percentage points or 13 per cent in comparison to the low educated reference category.

For Denmark the results indicate a somewhat more homogenous difference between educational levels across regions, with all regions displaying positive gradients. Only the capital region of Hovedstaden is characterised by slightly weaker positive associations between medium and high levels of educational attainment and first birth hazards than the rest of the country. In the Danish case, few other regions stand out.

The results for Finland show considerable regional variation in the general positive association between female educational attainment and first births. This regional variation exhibits similar patterns for medium level and highly educated women, with the smallest differentials in $\mathrm{SPPR}_{1}$ in the capital region of Helsinki-Uusimaa and the strongest positive educational gradients in more rural areas such as North \& East Finland, or West Finland. 
A comparison of French regions generally shows relatively neutral educational gradients in the transition to parenthood. More specifically, we found positive SPPR $_{1}$ differentials for medium educated women in Centre-Est and Ouest, whereas these differentials turn negative in the other French regions. This pattern also holds for highly educated women, but differentials are even smaller.

In the Netherlands, regional variation also seems limited and depends on whether medium level or highly educated women are regarded. When contrasting SPPR 1 between low and medium level educated groups, the Northern and Western region exhibit moderately stronger positive associations between medium educational attainment and first births. When contrasting $\mathrm{SPPR}_{1}$ between low and highly educated groups, the Western and Southern region display slightly stronger positive associations.

Norway exhibits considerable regional variation in the association between medium and particularly high levels of educational attainment and first births. The capital (Oslo) stands out with the largest $\mathrm{SPPR}_{1}$ differentials for both medium and especially highly educated women. Similar large $\mathrm{SPPR}_{1}$ differentials are documented for the region surrounding Oslo (Akershus) and the rural Hedmark og Oppland, while the two regions in the North (Trøndelag and Nord-Norge) exhibit the smallest positive educational gradients in first births.

Finally, regional findings for Sweden show that educational gradients are smallest in the urban region around Stockholm, and gradients in the South and upper north are also smaller than average. The strongest negative educational gradient for highly educated women is found in the central regions and lower-north of Sweden. 


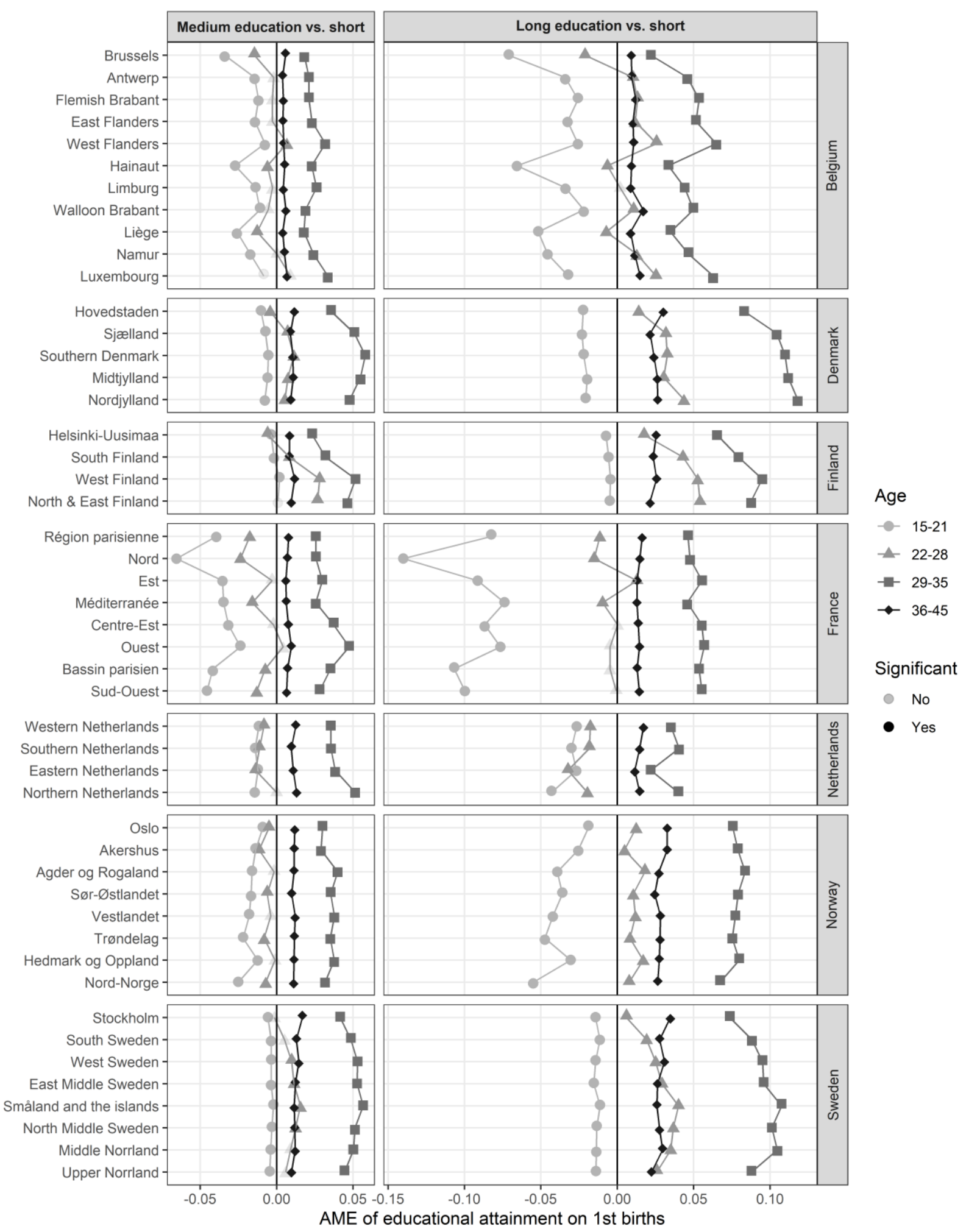

Fig.1 Average marginal effects of educational attainment on first births (individual-

level models), 2002-2005, BE, DK, FI, FR, NL, NO, SE 


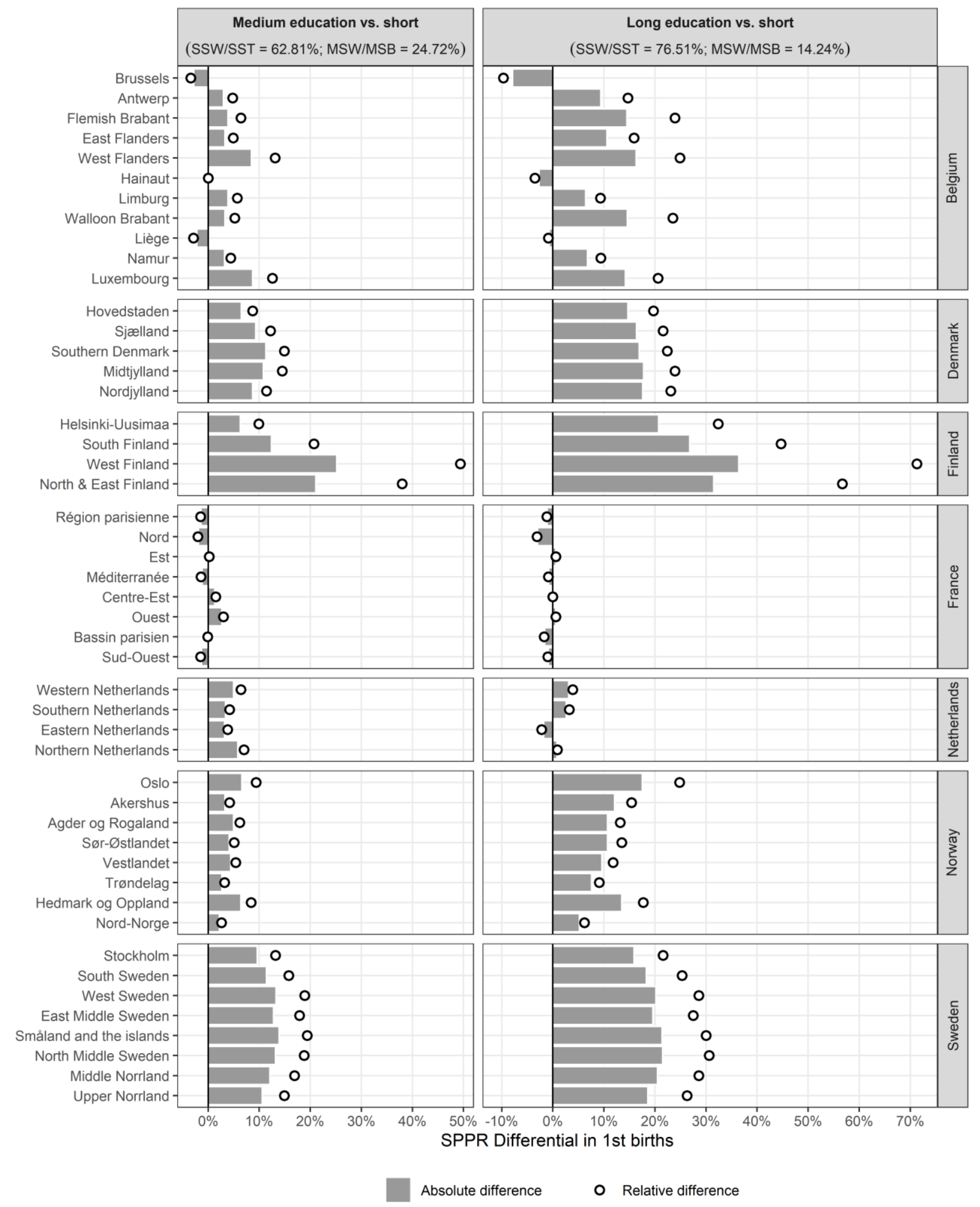

Fig.2 Absolute percentage point and proportional per cent educational differences in

$S P P R_{1}, 2002-2005, B E, D K, F I, F R, N L, N O, S E$ 
3.2 National and regional variation in the female educational gradient in second births

Figure 3 indicates that in all regions considered and particularly in the first three years of exposure after the first birth, second birth hazard schedules vary significantly by women's level of educational attainment, with mostly positive educational gradients. This finding is consistent with routinely documented findings with respect to second birth timing and a so-called "time-squeeze" - implying that higher educated women space their second birth closer to the first (Kreyenfeld, 2002). These effects are followed by a mixture of positive and negative associations between medium level or high education and second birth hazards for the 4-9 exposure category, and very limited educational differentials during later exposure periods which are characterised by extremely low second birth hazards in general. However, similarly to our findings for first births, considerable geographical variation exists in the educational differentials in second birth hazards. Particularly some French and also some Finnish regions stand out with significantly negative associations between medium level or higher education on the one hand and second birth hazards on the other.

Furthermore, figure 4 demonstrates that, similar to educational gradients in first births, a discussion of differential linkages between educational attainment and second birth hazards focussing on countries only masks considerable regional variation within countries. Model comparison tests indicate that allowing the educational gradient in second births to vary by subnational regions in addition to between country variation significantly contributes to the model $(\Delta-2 \mathrm{LL}: 887.01 ; \Delta$ df. $82 ; \mathrm{p}<0.000)$. Although the region-specific educational gradients in second births are clearly clustered by country, neglecting subnational regional variation would mask considerable heterogeneity. An estimated 63.55 per cent and 85.14 per cent of the total regional variation in the 
differential $\mathrm{SPPR}_{2}$ among medium level and highly educated women is situated between regions within countries (SSW/SST).

The results for Belgium indicate a flat educational gradient in second childbearing in the Brussels capital region. In addition, among the other regions, the magnitude of the educational gradient varies considerably depending on the region considered. The weakest positive educational gradients in $\mathrm{SPPR}_{2}$ are mostly found in Luxembourg, Walloon Brabant, and particularly Liège and Hainaut which also stood out as a result of relatively weak positive or even negative educational gradients in first births. These limited educational gradients in second births contrast with stronger positive $\mathrm{SPPR}_{2}$ differentials for highly educated groups in Antwerp, Flemish Brabant, East Flanders, and particularly West Flanders, which similarly to our results for first births, exhibits the strongest positive educational gradient in second births.

For Denmark the results show that the gradient for the medium-level educated is somewhat more stable across regions. However, the Hovedstaden capital region and Southern Denmark are characterised by larger positive associations between high levels of educational attainment and second birth hazards. This contrasts with our findings with respect to $\mathrm{SPPR}_{1}$, where especially the Danish capital region of Hovedstaden displayed smaller gradients that the rest of the country.

Regional differences in the educational gradient in second childbearing are limited to more neutral gradients for the urban Helsinki-Uusimaa capital region and South Finland, depending on whether we contrast medium or highly educated women to their lower educated counterparts. This pattern of regional differentiation is in line with our results 
for first births in which these regions display weaker positive or neutral educational gradients.

In France, we observe a divide between regions with positive educational gradients in second birth transitions (the capital region Région Parisienne in particular), and regions with negative gradients (e.g., the Eastern and Northern regions Nord and Est). This regional differentiation contrasts with the absence of noteworthy regional differentiation with respect to first births in France.

In the Netherlands, the Southern region stands out with a stronger positive educational gradient in second births and weaker positive associations in other regions. The Eastern Dutch region exhibits the weakest positive gradient, which is in line with its weaker positive or even negative educational gradient in first births.

Norway exhibits considerable variation between its subnational regions with respect to the educational gradient in second births, particularly when focussing on highly educated groups. Similar to the pattern for Denmark and France, Norway displays a pattern in which the capital (Oslo) and its surrounding urban region Akershus display the strongest positive association between high educational attainment and the progression to a second birth. With respect to the former, these results seem in line with results for first births as the Oslo capital region also displayed the strongest positive association between high educational attainment and first births.

Finally, findings for Sweden show limited regional variation in general. However, in line with our results for first births, the positive educational gradients in $\mathrm{SPPR}_{2}$ seem to be more attenuated both in the most densely populated Stockholm capital region, as well as in the least densely populated regions of Middle Norrland and Upper Norrland. 


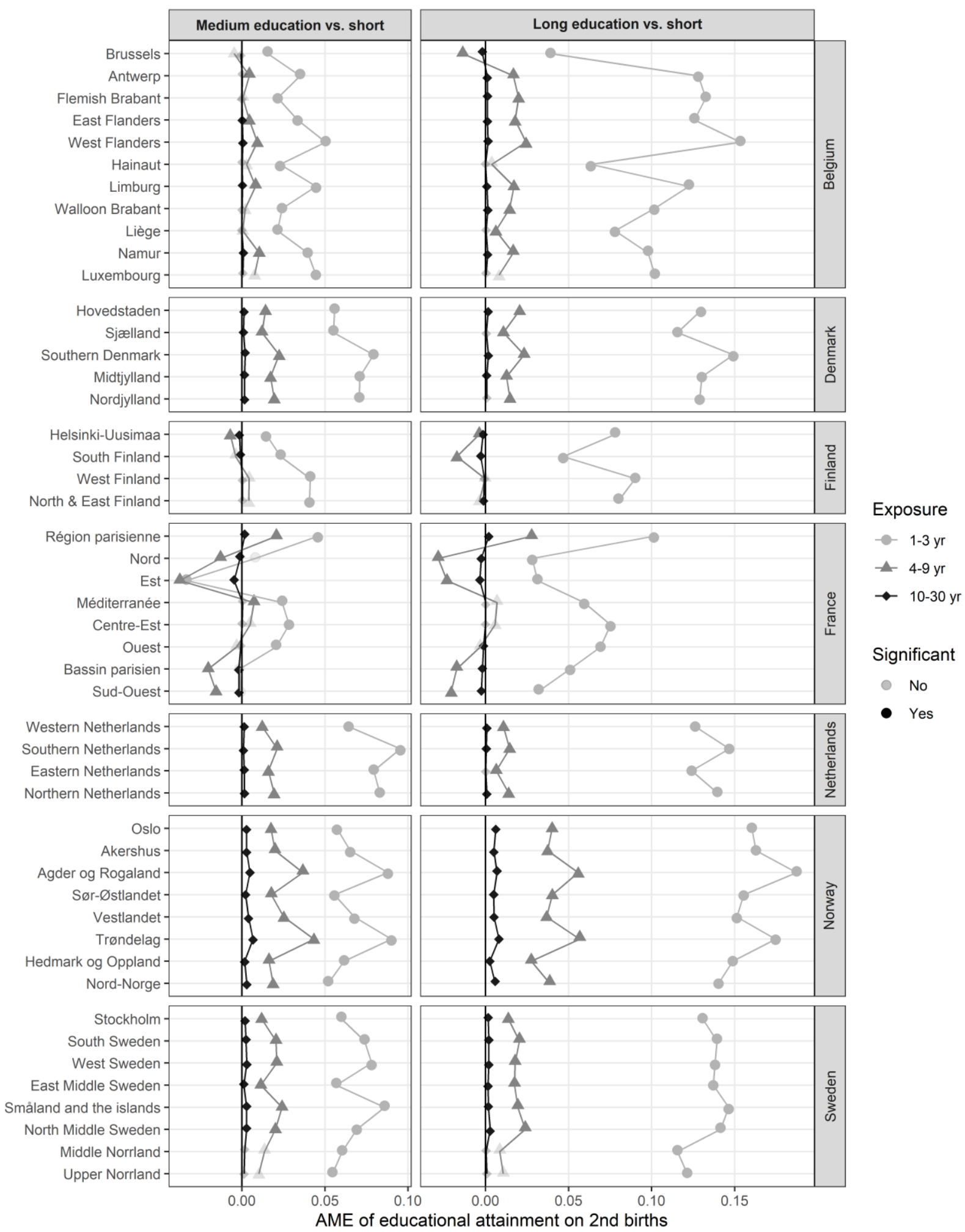

Fig.3 Average marginal effects of educational attainment on second births (individual-

level models), 2002-2005, BE, DK, FI, FR, NL, NO, SE 


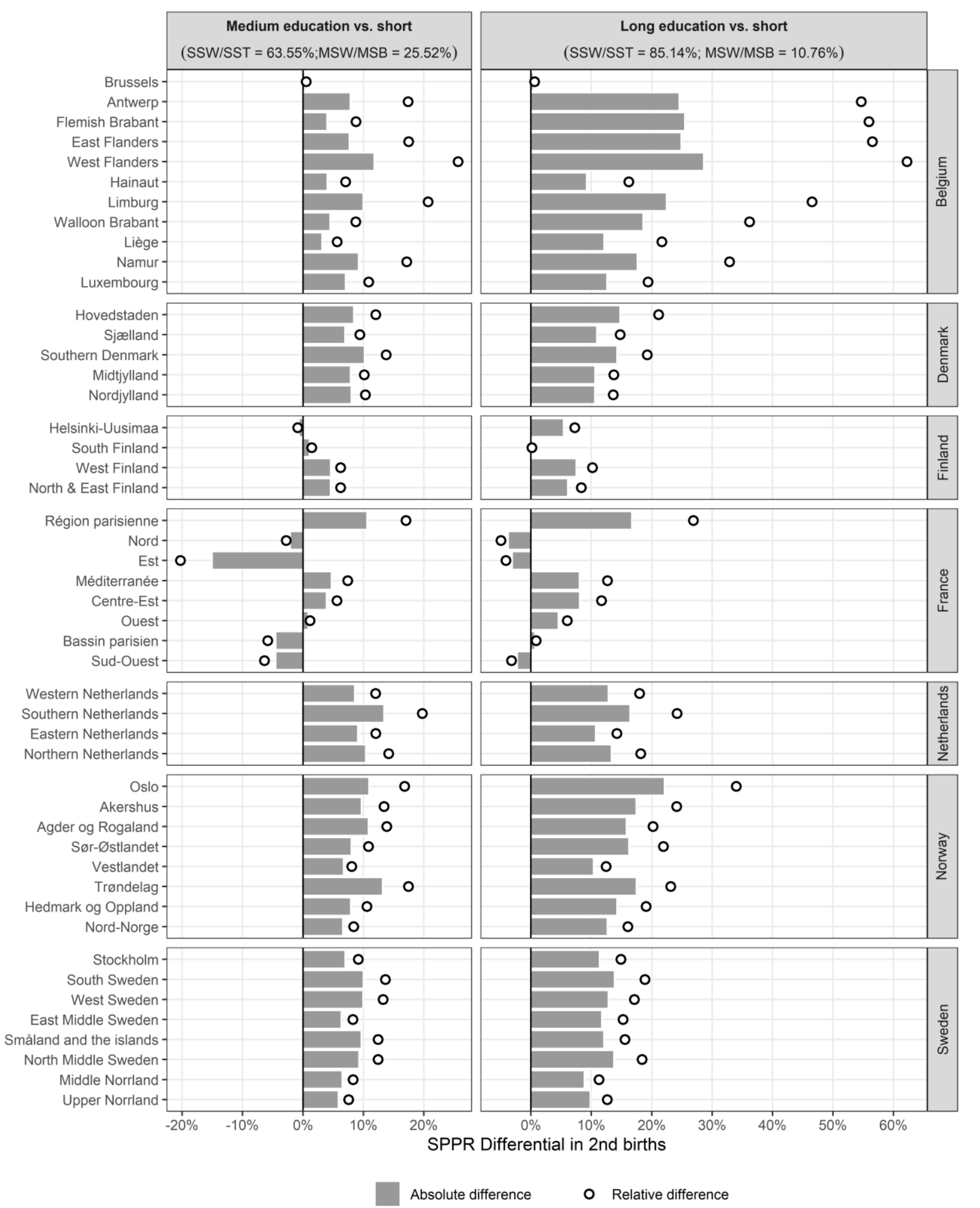

Fig.4 Absolute percentage point and proportional per cent educational differences in

$S P P R_{2}, 2002-2005, B E, D K, F I, F R, N L, N O, S E$ 
3.3 National and regional variation in the female educational gradient in third births

Figure 5 shows that the educational gradients in third births differ strongly from the mostly positive educational gradients in second births. The association between medium educational attainment and third birth hazards is mostly neutral to negative. Particularly medium level educated women exhibit lower birth hazards in the 1-3 and 4-9 exposure intervals, whereas in many Belgian and Danish regions, but also all Dutch and Norwegian regions, highly educated women display significantly positive differential third birth hazards in the first three years after the second birth. These U-shaped patterns have also been identified in previous literature as a pattern which more often occurs for third births than for second or first births (Neels \& De Wachter, 2010; Wood et al., 2014). However, consistent with findings for first and second births, differential third birth hazards by educational attainment exhibit considerable geographical variation. Model comparison tests indicate that allowing the educational gradient in third births to vary by subnational regions in addition to between country variation significantly contributes to the model $(\Delta$ -2LL: 537.76; $\Delta$ df. 82; $\mathrm{p}<0.000)$.

Furthermore, figure 6 shows that despite the fact that the average squared difference from the mean within a country is two to ten times smaller $(11.45 \%$ for medium vs. low and $50.85 \%$ for high vs. low) compared to the average squared difference between country means and the grand mean, assuming that regional variation can be captured by between country differences would be a mistake. Overall 43.89 per cent and 69.95 per cent of the total regional variation in the differential $\mathrm{SPPR}_{2}$ among medium level and highly educated women is situated between regions within countries (SSW/SST).

The results for Belgium indicate a consistently negative association between medium levels of educational attainment and $\mathrm{SPPR}_{3}$, with the strongest negative differential in the 
Brussels capital region. In addition, the regions Hainaut and Liège are also - in line with the results for first and second births - characterised by relatively strong negative $\mathrm{SPPR}_{3}$ differentials for highly educated groups. The remaining regions display neutral $\mathrm{SPPR}_{3}$ differentials.

Comparing the highly educated to lower educated women in Denmark, we only see small differences and lower levels of variation across regions compared to the other studied countries. However, we do find larger heterogeneity in relative differences between medium and low educated across regions than were evident for $\mathrm{SPPR}_{2}$ and particularly $\mathrm{SPPR}_{1}$. In the region Midtjylland the relative difference is limited to 13 per cent, whereas for the region of Sjælland - which also exhibited a relatively weak positive educational gradient in the progression to a second birth - the $\mathrm{SPPR}_{3}$ is 30 per cent lower than for the low educated.

The results for Finland also display larger subnational regional variation in the contrast between low and medium level educated groups, compared to the differentials between highly educated women and their low educated counterparts. In line with our results for the progression to second births in which West Finland exhibits the strongest positive educational gradient, this region is characterised by the weakest negative educational gradient in third births.

A comparison of the French regions shows quite some differentiation in the magnitude of a mostly negative educational gradient in third births across regions. The range of $\mathrm{SPPR}_{3}$ differentials is larger than in any other country studied. For both medium and highly educated women, the strongest negative gradient is observed in the relatively densely 
populated Northern Nord region, and very weak to neutral gradients are found in the Western region Ouest.

The Netherlands shows relatively small educational differences in general, but also limited regional variation, regarding the progression to a third birth. Similarly to our results for second births, the Southern region stands out due to more articulated positive associations between level of educational attainment and higher order childbearing.

In Norway, the results show a negative association between medium levels of educational attainment and third births in the capital and its surrounding region (Akershus) as well as in Nord-Norge. The other regions display more or less neutral or slightly positive (e.g. Trøndelag) differentials. Regarding differential $\mathrm{SPPR}_{3}$ between the highly and low educated groups in Norway, the picture changes and results indicate positive differentials in all regions beside Nord-Norge.

Finally, findings for Sweden show that Stockholm region has relatively smaller educational gradients, and the region with the most distinct pattern is the area of Småland where the negative educational gradient is smaller than in other regions, in particular for highly educated women. This was also the region with the largest positive educational gradient for transitioning to a first birth. 


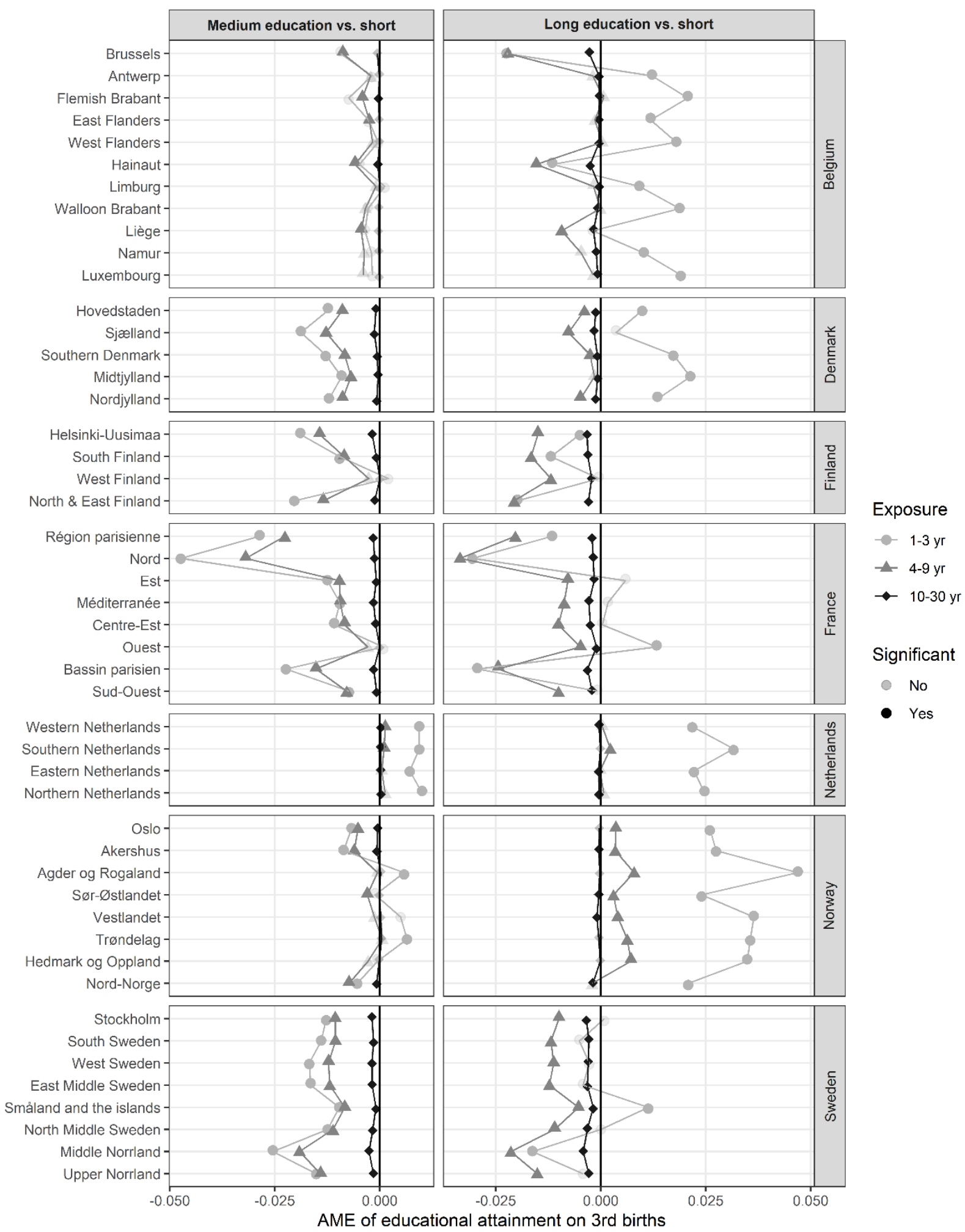

Fig.5 Average marginal effects of educational attainment on third births (individuallevel models), 2002-2005, BE, DK, FI, FR, NL, NO, SE 


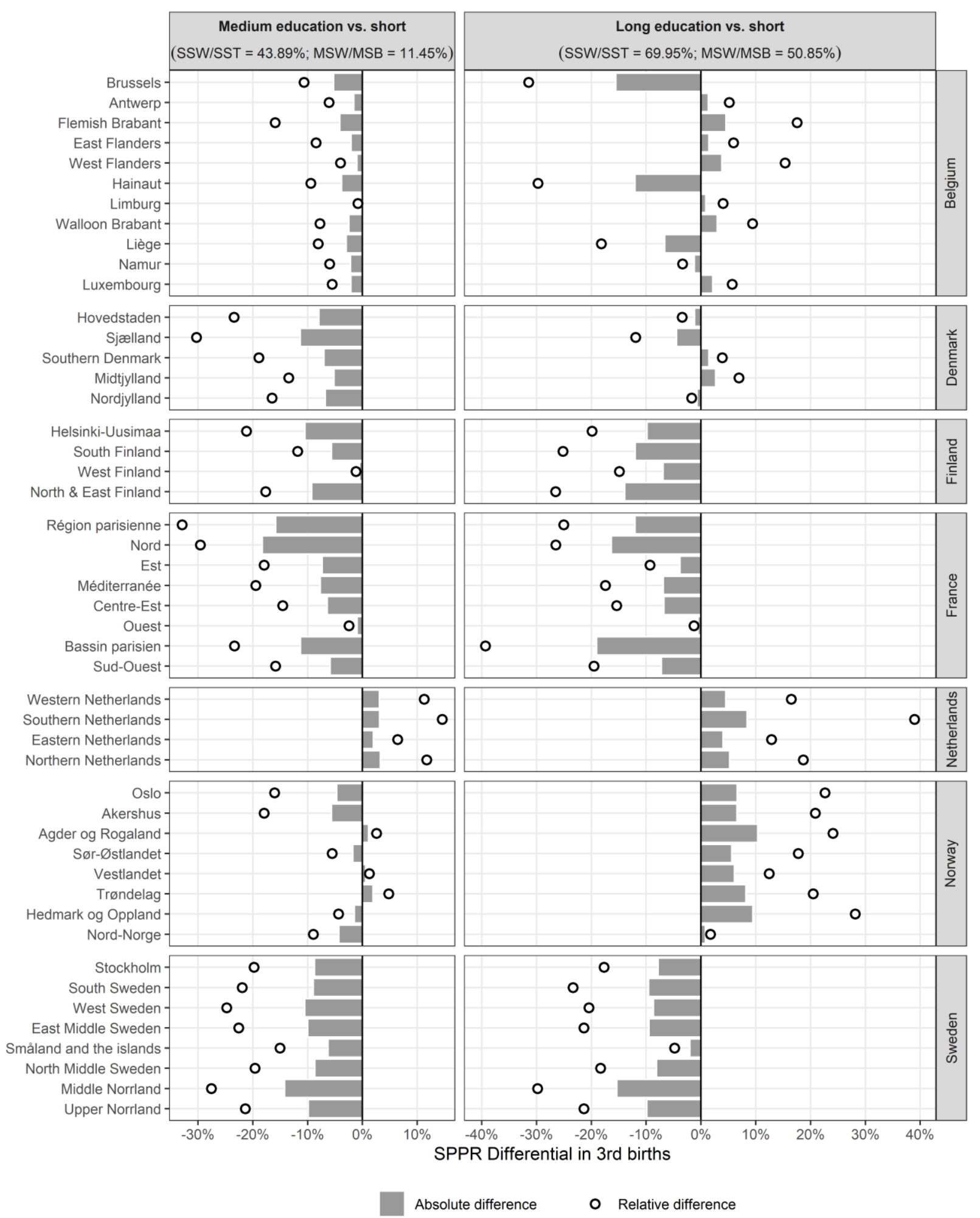

Fig.6 Absolute percentage point and proportional per cent educational differences in

$S P P R_{3}, 2002-2005, B E, D K, F I, F R, N L, N O, S E$ 


\section{Discussion \& Conclusion}

The relation between female education and fertility is a long-standing topic of central interest in demography. In recent decades the use of multi-country comparable survey data has allowed to document cross-national variation in women's educational gradient in fertility, which has been discussed in the context of country-level factors such as the availability of work-family reconciliation arrangements (Klesment et al., 2014; Wood et al., 2014). Western, and in particular Northern European countries, tend to stand out with relatively flat educational gradients in first births in combination with positive or Ushaped gradients in higher order births, particularly for more recent time periods or cohorts (Marika Jalovaara et al., 2019; Kravdal \& Rindfuss, 2008; Neels \& De Wachter, 2010; Wood et al., 2014). However, given the increasing availability of more detailed large-scale data sources, a new question has come to the fore: To which extent do educational gradients in fertility vary by subnational regions?

This study is among the first to document regional differences in women's educational gradient in fertility, using large-scale high-quality register data for seven Northern and Western European countries. To our knowledge, only one prior study has documented variation in the educational gradient of fertility across subnational regions for multiple countries; this study based on data from several European countries however focused on cohort total fertility only (Nisén et al., 2021). Our findings confirm our expectation that, although educational gradients are strongly clustered by country, considerable regional differences occur beyond the country averages. Drawing on both visual representations and quantitative indexes of regional variation, this study shows that the sub-national regional level matters and should be studied further. In the studied North-Western European countries, the magnitude of within-country regional differences is typically 
limited as compared to between-country differences, but still substantial proportions of the overall variation is situated within the countries. In the case of educational gradients in (synthetic) progression to first births, the average squared difference from the countrymean was four to seven times smaller than the average squared difference between countries, yet 63 to 76 per cent of the total regional variation is situated within countries. Similarly 64 to 85 per cent of the total regional variation in the progression to second births, and 44 to 70 per cent of the total regional variation in the progression to third births is situated within countries.

Depending on the country and parity group considered, our results indicate differentiation in the magnitude and direction of the educational gradient in fertility, by population density of the region. A prior study found within-country variation in the educational gradient of cohort total fertility of women by regional level of GDP in Europe, such that less negative gradients were associated with higher levels of GDP, but this pattern as well did not apply to all studied countries (Nisén et al., 2021). These results together may suggest that country characteristics affect the patterning of regional within-country variation in educational gradients in fertility. As providing explanations for subnational regional variation in the educational gradient in female fertility lies beyond the scope of this explorative and descriptive article, we invite other scholars to assess subnational regional variation in women's educational gradient in fertility in tandem with potential explanations for regional variation. Studies following this path can build on the novel approach and findings of this study. We argue that future work on this topic is likely to develop theories on local education-fertility nexuses and contextual moderators, but also allow to assess to which extent existing hypotheses for country-level variation and their explanations hold at the subnational level. 
From a methodological point of view, this study contributes to the available literature on educational gradients in fertility by combining a parity-specific discrete-time event history approach with the calculation of estimation-based synthetic parity progression ratios. This approach yields the benefit of providing both micro-level associations between birth hazard functions and educational attainment, and corresponding significance tests, as well as indicators of the direction and magnitude of parity-specific educational gradients at the aggregate level. Although this article is by no means the first to adopt such an approach (Neels, 2006; Wood \& Neels, 2019; Wood et al., 2014), this article has shown that the adoption of this approach is particularly beneficial when studying educational gradients in parity-specific fertility from a regional perspective. The further assessment of potential regional-level explanations for subnational variation in educational gradients in fertility is also likely to benefit from this approach, as microlevel hazard models allow to address the strength and significance of local factors on individual birth hazards, whereas estimate-based SPPRs provide aggregate-level information on the degree to which the potential impact of local characteristics is strong enough to explain regional differentiation and deviant patterns for specific localities.

Finally, five limitations and corresponding avenues for future research should be highlighted. First, this study covered countries in a particular region, Northern and Western Europe. The results are not be generalised to other parts of Europe or to other highly developed countries, often characterized by less family-friendly environments and stronger negative or weaker positive educational gradients in fertility. Although the data requirements for a regional analysis remain high, and in some cases unachievable, ideally future studies would shed light on regional patterning of educational gradients in fertility also in other contexts. Second, first generation migrants are also excluded from the sample 
due to the strong interrelations between migration and fertility (Milewski, 2010). This implies that this source of within-country variation in the educational gradient is not taken into account and should be addressed in future work. Third, although the rich combination of datasets provides a unique opportunity to address parity-specific regional educational gradients in female fertility, future work should consider potential avenues to use smaller regional units. It is likely that larger regions used in this study mask considerable heterogeneity in both contextual features as well as educational gradients in fertility. Fourth, although the mid-2000s observational window was chosen as a result of the fact that some Northern and Western European countries seemed to display shifts in the education-fertility nexus around the turn of the century, future research on later time periods or comparing different time periods would further enhance our understanding of the temporal variations in - and potentially also context-contingencies of - region-specific educational gradients in fertility. Fifth and finally, although men's fertility has attracted growing interest in recent decades, it is safe to say that our knowledge on educational gradients in male fertility is still lagging behind. It is self-evident that an investigation into regional differentiation in male fertility by level of education would be a fruitful next step.

\section{References}

Aassve, A., Fuochi, G., \& Mencarini, L. (2014). Desperate Housework Relative Resources, Time Availability, Economic Dependency, and Gender Ideology Across Europe. Journal of Family Issues, 35(8), 1000-1022.

Adsera, A. (2017). The future fertility of highly educated women: the role of educational composition shifts and labor market barriers. Vienna Yearbook of Population Research, 15, 19-25.

Adserà, A. (2017). Education and fertility in the context of rising inequality. Vienna Yearbook of Population Research,, 15, 19-25. 
Andersson, G., Duvander, A.-Z., \& Hank, K. (2004). Do child-care characteristics influence continued child bearing in Sweden? An investigation of the quantity, quality, and price dimension. Journal of European Social Policy, 14(4), 407-418.

Andersson, G., Rønsen, M., Knudsen, L. B., Lappegård, T., Neyer, G. R., Skrede, K., . . . Vikat, A. (2009). Cohort fertility patterns in the Nordic countries Demographic Research, 20(14), 313-352.

Baizan, P. (2009). Regional child care availability and fertility decisions in Spain. Demographic Research, 21(27), 803-842. doi:10.4054/DemRes.2009.21.27

Baizan, P., \& Martín-García, T. (2006). Endogeneity and joint determinants of educational enrolment and first birth timing in France and West Germany [Joint determinants of educational enrolment and first birth timing in France and West Germany]. Genus, 62(2), 89-117.

Bakker, B. F. M., van Rooijen, J., \& van Toor, L. (2014). The System of social statistical datasets of Statistics Netherlands: An integral approach to the production of register-based social statistics. Statistical Journal of the IAOS, 30, 411-424. doi:10.3233/SJI-140803

Basten, S., Huinink, J., \& Klüsener, S. (2011). Spatial variation of sub-national fertility trends in Austria, Germany and Switzerland. Comparative Population Studies, 36(2-3).

Beaujouan, E., Brzozowska, Z., \& Zeman, K. (2016). The limited effect of increasing educational attainment on childlessness trends in twentieth-century Europe, women born 1916-65. Population Studies, 70(3), 275-291. doi:10.1080/00324728.2016.1206210

Beaujouan, E., Sobotka, T., \& Brzozowska, Z. (2013). Education and sex differences in intended family size in Europe, 1990s and 2000s. Paper presented at the Changing families and fertility choices, Oslo, Norway.

Becker, G. (1981). A Treatise on the Family. London: Harvard University Press.

Becker, G., \& Lewis, H. G. (1973). On the interaction between the quantity and quality of children. The Journal of Political Economy, 81(2), 279-288.

Bergsvik, J. (2019). Linking neighbors' fertility. Third births in Norwegian neighborhoods. Comparative Population Studies, 45(Oct. 2020). doi:https://doi.org/10.12765/CPoS-2020-21

Breen, R., \& Andersen, S. H. (2012). Educational Assortative Mating and Income Inequality in Denmark. Demography, 49(3), 867-887. doi:10.1007/s13524-0120111-2

Couet, C. (2006). L'Échantillon Démographique Permanent de l'Insee. Courrier statistique, $n^{\circ} 117-119,5-14$.

Davie, E., \& Mazuy, M. (2010). Fécondité et niveau d'études des femmes en France à partir des enquêtes annuelles de recensement. [Women's Fertility and Educational Level in France: Evidence from the Annual Census Surveys]. Population, 65(3), 475-511. doi:10.3917/popu.1003.0475

Dawkins, C. J. (2006). Are Social Networks the Ties that Bind Families to Neighborhoods? Housing $\quad$ Studies, 21(6), 867-881. doi:10.1080/02673030600917776

de Beer, J., \& Deerenberg, I. (2007). An Explanatory Model for Projecting Regional Fertility Differences in the Netherlands. Population Research and Policy Review, 26(5), 511-528. doi:10.1007/s11113-007-9040-y 
De Wachter, D., \& Neels, K. (2011). Educational differentials in fertility intentions and outcomes: family formation in Flanders in the early 1990s. Vienna Yearbook of Population Research, 9, 227-258.

Deboosere, P., \& Willaert, D. (2004). Codeboek algemene socio-economische enquête 2001. Working Paper 2004-1. Steunpunt Demografie Vakgroep Sociaal Onderzoek (soco) Vrije Universiteit Brussel. Brussels.

Dribe, M., \& Nystedt, P. (2013). Educational Homogamy and Gender-Specific Earnings: Sweden, 1990-2009. Demography, 50(4), 1197-1216. doi:10.1007/s13524-0120188-7

Esping-Andersen, G., \& Billari, F. C. (2015). Re-theorizing Family Demographics. Population and Development Review, 41(1), 1-31.

Fox, J., Klüsener, S., \& Myrskylä, M. (2018). Is a Positive Relationship Between Fertility and Economic Development Emerging at the Sub-National Regional Level? Theoretical Considerations and Evidence from Europe. European Journal of Population. doi:10.1007/s10680-018-9485-1

Goldin, C. (2004). The Long Road to the Fast Track: Career and Family. The ANNALS of the American Academy of Political and Social Science, 596(1), 20-35. doi:10.1177/0002716204267959

Goldscheider, F., Bernhardt, E., \& Lappegard, T. (2015). The Gender Revolution: A Framework For Understanding Changing Family and Demographic Behaviour. Population and Development Review, 41(2), 207-239.

Hank, K. (2002). Regional Social Contexts and Individual Fertility Decisions: A Multilevel analysis of First and Second Births in Western Germany. European Journal of Population, 18, 281-299.

Hank, K., \& Kreyenfeld, M. (2003). A Multilevel Analysis of Child Care and Women's Fertility Decisions in Western Germany. Journal of Marriage and Family, 65(3), 584-596.

Hart, R. K. (2015). Earnings and first birth probability among Norwegian men and women 1995-2010. Demographic Research, 33(38), 1067-1104.

Hoem, B., \& Hoem, J. M. (1989). The impact of women's employment on second and third births in modern Sweden. Population Studies, 43(1), 47-67.

Hudde, A. (2018). Societal Agreement on Gender Role Attitudes and Childlessness in 38 Countries. European Journal of Population, 34(5), 745-767. doi:10.1007/s10680017-9459-8

Jalovaara, M., \& Miettinnen, A. (2013). Does his paycheck also matter? The socioeconomic resources of co-residential partners and entry into parenthood in Finland. Demographic Research, 28(31), 881-916.

Jalovaara, M., Neyer, G., Andersson, G., Dahlberg, J., Dommermuth, L., Fallesen, P., \& Lappegård, T. (2019). Education, Gender, and Cohort Fertility in the Nordic Countries. European Journal of Population, 35(3), 563-586. doi:10.1007/s10680018-9492-2

Kil, T., Wood, J., \& Neels, K. (2018). Parental leave uptake among migrant and native mothers: Can precarious employment trajectories account for the difference? Ethnicities, 18(1). doi:doi:10.1177/1468796817715292

Klesment, M., Puur, A., Rahnu, L., \& Sakkeus, L. (2014). Varying association between education and second births in Europe: Comparative analysis based on the EUSILC data. Demographic Research, 31(27), 813-860. 
Köppen, K. (2006). Second births in western Germany and France. Demographic Research, 14(14), 295-330.

Kornstad, T., \& Rønsen, M. (2018). Women's Wages and Fertility Revisited Evidence from Norway. European Journal of Population, 34(4), 491-518. doi:10.1007/s10680-017-9435-3

Kravdal, O. (1992). The Emergence of a Positive Relation Between Education and Third Birth Rates in Norway with Supportive Evidence from the United States. Population Studies, 46(3), 459-475.

Kravdal, O. (2001). The High Fertility of College Educated Women in Norway: An Artefact of the Separate Modelling of Each Parity Transition. Demographic Research, 5(6), 187-216.

Kravdal, O. (2007). Effects of current education on second- and third-birth rates among Norwegian women and men born in 1964: Substantive interpretations and methodological issues. Demographic Research, 17(9), 211-246.

Kravdal, O., \& Rindfuss, R. R. (2008). Changing Relationships between Education and Fertility: A Study of Women and Men Born 1940 to 1964. American Sociological Review, 73(5), 854-873.

Kreyenfeld, M. (2002). Time-squeeze, partner effect or selfselection? An investigation into the positive effect of women's education on second birth risks in West Germany. Demographic Research, 7(2), 15-48.

Kreyenfeld, M., \& Andersson, G. (2014). Socioeconomic differences in the unemployment and fertility nexus: Evidence from Denmark and Germany. Advances in Life Course Research, 21, 59-73.

Kreyenfeld, M., \& Hank, K. (2000). Does the availability of childcare influence the employment of mothers? Findings from western Germany. Population Research and Policy Review, 19(2000), 317-337. doi:https://doi.org/10.1023/A:1026556309080

Kulu, H. (2005). Migration and fertility: Competing hypotheses re-examined. . European Journal of Population, , 21(1), 51-87.

Kulu, H. (2013). Why Do Fertility Levels Vary between Urban and Rural Areas? Regional Studies, 47(6), 895-912. doi:10.1080/00343404.2011.581276

Kulu, H., \& Washbrook, E. (2014). Residential context, migration and fertility in a modern urban society. Advances in Life Course Research, 21, 168-182.

Lappegård, T., \& Ronsen, M. (2005). The Multifaceted Impact of Education on Entry into Motherhood. European Journal of Population, 21(1), 31-49.

Lesthaeghe, R., \& Neels, K. (2002). From the First to the Second Demographic Transition: An Interpretation of the Spatial Continuity of Demographic Innovation in France, Belgium and Switzerland. European Journal of Population, 18(4), 325-360.

Lesthaeghe, R., \& Surkyn, J. (1988). Cultural Dynamics and Economic Theories of Fertility Change. Population and Development Review, 14(1), 1-45.

Lesthaeghe, R., \& Van de Kaa, D. (1986). Twee demografische transities? In R. Lesthaeghe \& D. Van de Kaa (Eds.), Bevolking: groei en krimp. Deventer: Van Loghum Slaterus.

Liefbroer, A. C., \& Corijn, M. (1999). Who, What, Where and When? Specifying the Impact of Educational Attainment and Labour Force Participation on Family Formation. European Journal of Population, 15, 45-75. 
Liu, S. X., Jia, C. Y., Ambrus, C., Neels, A., Labat, G., \& Decurtins, S. (2006). Onedimensional mu-chloromanganese(II)-tetrathiafulvalene (TTF) coordination compound. Inorganic Chemistry, 45(8), 3152-3154. doi:Doi 10.1021/Ic060056f

Marx, I., \& Vandelannoote, D. (2014). Matthew Runs Amok: The Belgian Service Voucher Scheme. In Carbonnier C. \& M. N. (Eds.), The Political Economy of Household Services in Europe. Work and Welfare in Europe. London: Palgrave Macmillan.

Marynissen, L., Wood, J., \& Neels, K. (2021). Mothers and Parental Leave in Belgium: Social Inequalities in Eligibility and Uptake. Social Inclusion, 9(2), 13. doi:10.17645/si.v9i2.3834

Miettinen, A., Rotkirch, A., Szalma, I., Donno, A., \& Tanturri, M. L. (2015). Increasing childlessness in Europe: Time trends and country differences. Families and Societies. Working Paper Series, 3.

Milewski, N. (2010). Fertility of Immigrants: A Two-Generational Approach in Germany. University Rostock, Rostock.

Muresan, C., \& Hoem, J. M. (2010). The negative educational gradients in Romanian fertility. Demographic Research, 22(4), 95-114.

Neels, K. (2006). Reproductive Strategies in Belgian Fertility, 1960-1990.

Neels, K., \& De Wachter, D. (2010). Postponement and recuperation of Belgian fertility: how are they related to rising female educational attainment? Vienna Yearbook of Population Research, 8, 77-106.

Neels, K., Murphy, M., Ní Bhrolcháin, M., \& Beaujouan, É. (2017). Rising Educational Participation and the Trend to Later Childbearing. Population and Development Review, 43(4), 667-693. doi:10.1111/padr.12112

Neels, K., Theunynck, Z., \& Wood, J. (2012). Economic recession and first births in Europe: recession-induced postponement and recuperation of fertility in 14 European countries between 1970 and 2005. International Journal of Public Health, 58(1), 43-55.

Neyer, G., Hoem, J. M., \& Andersson, G. (2017). Education and Childlessness: The Influence of Educational Field and Educational Level on Childlessness among Swedish and Austrian Women. In M. Kreyenfeld \& D. Konietzka (Eds.), Childlessness in Europe: Contexts, Causes, and Consequences (pp. 183-207). Cham: Springer International Publishing.

Nisén, J., Klüsener, S., Dahlberg, J., Dommermuth, L., Jasilioniene, A., Kreyenfeld, M., .. . Myrskylä, M. (2021). Educational Differences in Cohort Fertility Across Sub-national Regions in Europe. European Journal of Population, 37(1), 263295. doi:10.1007/s10680-020-09562-0

OECD. (1999). Classifying educational programmes: Manual for ISCED-97 implementation in OECD countries: OECD Paris.

OECD. (2018). OECD Database: Educational attainment and labour-force status.

Olah, L. S. (2003). Gendering fertility: Second births in Sweden and Hungary. Population Research and Policy Review, 22, 171-200. doi:https://doi.org/10.1023/A:1025089031871

Perelli-Harris, B. (2008). Ukraine: On the border between old and new in uncertain times. Demographic Research, 19(29), 1145-1178.

Population Council. (2006). Policies to Reconcile Labor Force Participation and Childbearing in the European Union. Population and Development Review, 32(2), 389-393. 
Rindfuss, R. R., Guilkey, D. K., Morgan, S. P., \& Kravdal, O. (2010). Child-Care Availability and Fertility in Norway. Population and Development Review, 36(4), 725-748.

Ruokolainen, A., \& Notkola, I.-L. (2002). Familial, situational and attitudinal determinants of third-birth intentions and their uncertainty. Yearbook of Population Research in Finland, 38, 179-206.

Snyder, R. (2001). Scaling Down: The Subnational Comparative Method. Studies in Comparative International Development (SCID) 36(1), 93-110.

Sobotka, T., Beaujouan, E., \& Van Bavel, J. (2017). Introduction: education and fertility in low-fertility settings. Vienna Yearbook of Population Research, 2017(15), 116.

Sobotka, T., Zeman, K., Potancokova, M., Eder, J., Brzozowska, Z., Beaujouan, E., \& Matysiak, A. (2015). European fertility datasheet 2015. Retrieved from

Statistics Norway. (2017). National education database - Documentation. Retrieved from https://www.ssb.no/en/omssb/tjenester-og-verktoy/data-tilforskning/utdanning/om-nasjonal-utdanningsdatabase

Statistics Norway. (2021). Population - about the statistics. Retrieved from https://www.ssb.no/en/befolkning/folketall/statistikk/befolkning?fane=om

Testa, M. R. (2014). On the positive correlation between education and fertility intentions in Europe: Individual-and-country-level evidence. Advances in Life Course Research, 21, 28-42.

Thomas, M. J. (2019). Employment, education, and family: Revealing the motives behind internal migration in Great Britain. Population, Space and Place, 25(4), e2233. doi:10.1002/psp.2233

Van Bavel, J., Klesment, M., Beaujouan, E., Brzozowska, Z., Puur, A., Reher, D., . . . Zeman, K. (2018). Seeding the gender revolution: Women's education and cohort fertility among the baby boom generations. Population Studies, 72(3), 283-304. doi:10.1080/00324728.2018.1498223

Van Bavel, J., \& Rozanska-Putek, J. (2010). Second birth rates across Europe: interactions between women's level of education and child care enrolment. Vienna Yearbook of Population Research, 8, 107-138. doi:10.1553/populationyearbook2010s107

van de Kaa, D. J., \& Lesthaeghe, R. J. (1986). Bevolking, groei en krimp: Van Loghum Slaterus.

Van Lancker, W. (2017). Reducing Inequality in Childcare Service Use across European Countries: What (if any) Is the role of Social Spending? Social Policy \& Administration(52), 271-292. doi:10.1111/spol.12311

Van Lancker, W., \& Ghysels, J. (2012). Who benefits? The social distribution of subsidized childcare in Sweden and flanders. Acta Sociologica, 55(2), 125-142.

Vignoli, D., Drefahl, S., \& De Santis, G. (2012). Whose job instability affects the likelihood of becoming a parent in Italy? A tale of two partners. Demographic Research, 26(2), 41-62.

Vikat, A. (2004). Women's Labor Force Attachment and Childbearing in Finland. Demographic Research, Special Collection 3(8), 177-212.

Wood, J. (2019). Social differentials in the effect of formal childcare on the transition to parenthood?: An assessment of varying effects by education, working hours and migration background. Advances in Life Course Research, 42, 100309. doi:https://doi.org/10.1016/j.alcr.2019.100309 
Wood, J., \& Neels, K. (2017). First a job, then a child? Subgroup variation in women's employment-fertility link. Advances in Life Course Research, 33, 38-52.

Wood, J., \& Neels, K. (2019). Local Childcare Availability and Dual-Earner Fertility: Variation in Childcare Coverage and Birth Hazards Over Place and Time. European Journal of Population, 35(5), 913-937. doi:10.1007/s10680-018-95104

Wood, J., Neels, K., \& Kil, T. (2014). The educational gradient of childlessness and cohort parity progression in 14 low fertility countries. Demographic Research, 31(46), 1365-1416. 